\title{
A WELL-OXYGENATED CELLS ENVIRONMENT MAY HELP TO FIGHT AGAINST PROTEIN GLYCATION
}

\author{
BÉATRICE MERCIER ${ }^{1}$, JOSIANE PROST ${ }^{1}$, and MICHEL PROST ${ }^{2}$
}

${ }^{1}$ Université de Bourgogne, Dijon, France

Faculté des Sciences de la Vie, UPRES EA 4183 "Lipides \& Signalisation Cellulaire"

${ }^{2}$ Lara-Spiral SA, Couternon, France

\begin{abstract}
Objectives: Normoglycemic Wistar rats' Glycated Hemoglobin Levels (GHL) showed a time-dependent difference between control groups and those exposed to regular inhalation of peroxidizing extracts of turpentine. These extracts were able to optimize the oxygen permeation at the cellular level during and subsequently to a breathing session. The more the rats breathed turpentine peroxidized vapor, the lower their GHL was. This study was designed to confirm, in ex-vivo blood samples, the impact of peroxidizing extract on the GHL. Materials and Methods: Red blood cells were separated from plasmas by centrifugation. Plasmas were treated by peroxidizing and non-peroxidizing turpentine vapor or untreated (control), then combined with washed red blood cells three hours before evaluation. Glycation of hemoglobin proteins was quantified according to the Habeed's method. Results: The ex-vivo experiments showed that the peroxidizing terpenes reduced the GHL after a three-hour contact. So did oxidized terpenes. Controls and the volatile component of the expended essential oil showed the opposite results. Conclusion: Optimal oxygenation, especially when facilitated by the peroxidized volatile component of the essential oil of turpentine, can protect organisms (mammals in this study) from protein glycation. Optimizing oxygenation can also reduce the GHL of treated blood samples after three hours of incubation.
\end{abstract}

Key words:

Bol d'Air Jacquier®, Peroxidizing terpenes, Glycated hemoglobin, Oxygen

\section{INTRODUCTION}

The "Bol d'Air Jacquier®" device generates peroxidizing volatile terpenes from organic essential oil of turpentine (natural extract from Pinus pinaster). These peroxidizing terpenes are inhaled and bond with hemoglobin. The unstable compounds comprising hemoglobin, pinenes and oxygen are able to deliver oxygen to cells more efficiently than hemoglobin alone [1,2]. During previous studies designed to evaluate the capability of the device to counteract free radicalization [2,3] and due to the fact that glycated proteins generated free radicals, we decided to evaluate:
- the rate of glycated hemoglobin in the blood of the tested rats' blood samples,

- in ex-vivo blood samples, the impact of peroxidizing Pinus pinaster volatile terpenes and the non-peroxidizing ones on the GHL, from new, old (oxidized) and expended essential oil of turpentine.

\section{MATERIAL AND METHODS}

\section{Evaluation of rats' glycated hemoglobin}

Three series of Wistar rats were purchased from Dépré (F-18230 Saint Doulchard). All of them were kept caged

Received: August 16, 2010. Accepted: December 12, 2010.

Address reprint request to B. Mercier, UPRES EA 4183 "Lipides \& Signalisation Cellulaire", Faculté des Sciences de la Vie, Université de Bourgogne 6, Boulevard Gabriel, F-21000 Dijon, France (e-mail: beamercier@laposte.net). 
in groups consisting of four to six subjects in a room with a 12-hour light/dark cycle at an average temperature of $24^{\circ} \mathrm{C}$ and a humidity of $60 \%$. The rats were maintained on a standard diet of laboratory rat chow (lab-blocks, from Scientific Animal Food \& Engineering (SAFE) F-89290 AUGY). Food and tap water were freely available. Vitamin and mineral salt levels were conformed to recommended needs [4]. We followed the general guidelines for the care and use of laboratory animals recommended by the Council of European Communities [5]. The rats were exposed to 3-, 6- or 9-minute breathing sessions, from one session per two weeks to three sessions per week. The "peroxidizing" rats were regularly subjected to a 3-, 6- or 9-minute session with the Bol d'Air ${ }^{\circledR}$ device (they breathed peroxidizing terpens $=$ volatile transformed parts of Pinus pinaster turpentine essential oil). The "control" rats regularly had 3-, 6- or 9-minute sessions of breathing water vapor; one group (the "non-peroxidizing" one) breathed the Pinus pinaster volatile terpenes without the transformation conducted with oxygen, during a 6-minute session.

\section{Rate of glycated hemoglobin blood sample}

Blood for the ex-vivo experiments was given by F-Marcigny's veterinary office. Plasma was obtained by lowspeed centrifugation (1600 g for $10 \mathrm{~min}$ ). Red blood cells were washed with the KRL buffer (300 mosm/l). Plasmas were diluted in the KRL buffer (300 mosm/l, v:v 1:12) and treated or not (control) for 3 minutes. Washed red blood cells were combined 3 hours before evaluation with untreated (control) and treated plasma (treated plasma is plasma that was blended with peroxidizing and nonperoxidizing volatile components of organic essential oil of turpentine, by means of a bubbling effect generated by the Bol d'Air Jacquier ${ }^{\circledR}$ device). Glycation of hemoglobin proteins was quantified by measuring the percentage of derived amino acid residues using the TNBS assay according to the Habeed's method [6].

Statistical analysis of data was carried out using the Statistica $5{ }^{\circledR}$ (Statsoft, Tulsa, OK, USA) software. The data is fully presented as means \pm standard deviation $( \pm S D)$. It was tested by one-way and/or two-way analysis of variance (Anova-Manova). The difference was considered statistically significant at $\mathrm{p}<0.05$.

\section{RESULTS}

First, as seen in Figure 1, we observed a lower level of glycated hemoglobin in normoglycemic tested Wistar rats, compared with control groups, in a dose-dependent fashion. Indeed, the more the rats breathed vapor from the Bol d'Air ${ }^{\circledR}$, the lower their glycated hemoglobin level was.

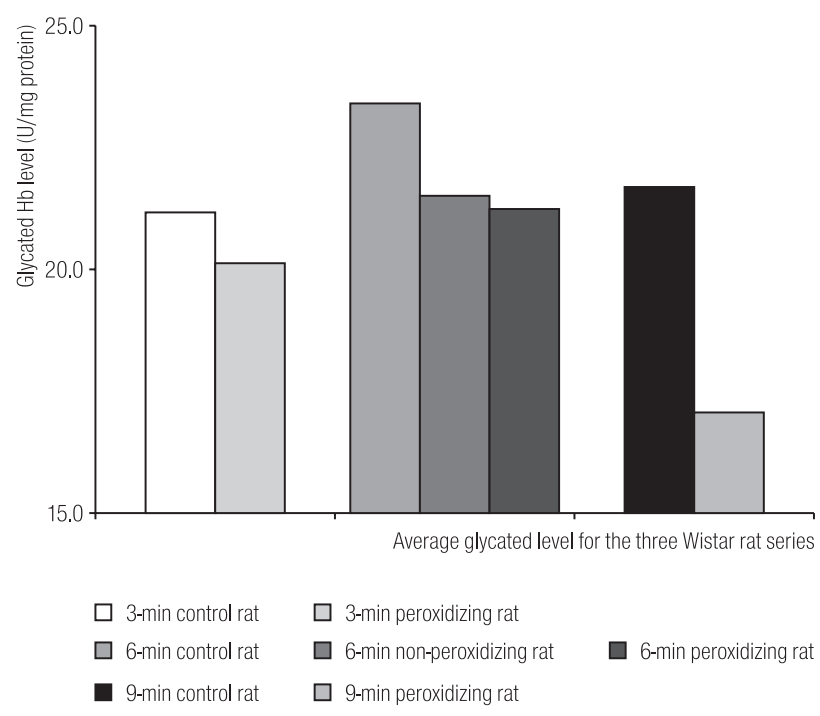

Three series of male Wistar rats are exposed to 3-, 6- or 9-minute breathing sessions (of water vapor for control, peroxidizing and non-peroxidizing terpens for the other series).

For statistical analysis (one-way analysis of variance - Anova Manova), a difference with $\mathrm{p}<0.05$ was considered statistically significant. Values of the figure are mean values \pm SD.

For the 3-min series: control group $=21.2 \pm 8$; peroxidizing group $=20.1 \pm 7 ; \mathrm{p}=0.7 ; \mathrm{n}=4$ /group, with 5 different swabs. For the 6-min series: control group $=23.4 \pm 5$; non-peroxidizing group $=21.5 \pm 7$; peroxidizing group $=21.2 \pm 5 ; p=0.16$; $\mathrm{n}=6 /$ group, with 6 different swabs.

For the 9-min series: control group $=21.7 \pm 6$; peroxidizing group $=17.1 \pm 8 ; \mathrm{p}=0.059 ; \mathrm{n}=5$ /group, with 5 different swabs

Fig. 1. Average levels of glycated hemoglobin of the 3-, 6and 9-min normoglycemic Wistar rats. 


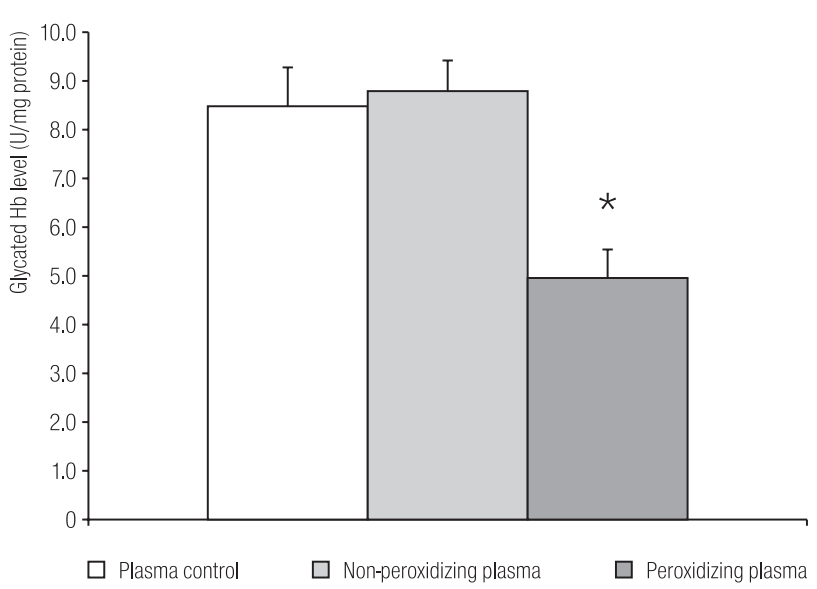

Fresh ox blood is separated into red blood cells (RBCs) and plasma by centrifugation.

RBCs are washed with KRL buffer then placed in contact, 3 hours before evaluation, with non-treated plasma (control) and treated plasma samples. The treatment is to bubble peroxidizing and non-peroxidizing volatile part of an organic essential oil of turpentine into the plasma samples, during 3 minutes. The essential oil of turpentine is freshly hydro-distilled.

Values of the figure are mean values $\pm \mathrm{SD} ; \mathrm{n}=3$ for the control plasma, $\mathrm{n}=3$ for non-peroxidizing plasma and $\mathrm{n}=6$ for peroxidizing plasma.

$p<0.05$ peroxidized plasma versus non-peroxidizing and control one.

Fig. 2. Average levels of glycated hemoglobin from ex-vivo ox blood - first study.

Relating to the ex-vivo tests, in Figure 2, we obtained a significantly reduced GHL with peroxidizing treated plasma versus the untreated (control) and non-peroxidizing treated plasma. In this case, the terpenes-rich oil was newly obtained by hydro-distillation of the pine resin.

Contrasting results were obtained with another three-hour incubation of washed red blood cells and plasmas (see Figure 3). In this case, we obtained a reduced GHL with peroxidizing treated plasma and non-peroxidizing treated plasma vs. the untreated one (control). The expended essential oil of turpentine came from a closed, half-full bottle several years old. In other words, the terpenes-rich oil used in this experiment was oxidized.

No more differences among the three samples are seen in Figure 4. Here, the terpenes-rich oil came from the

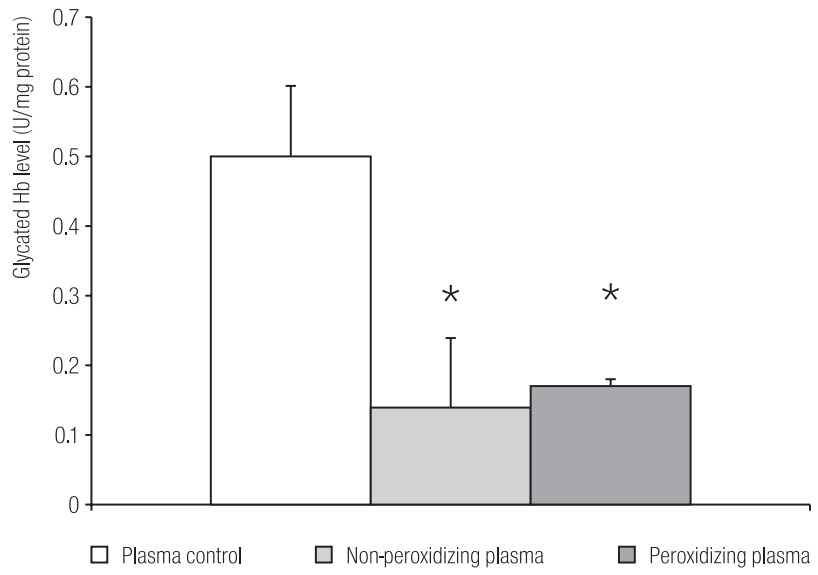

Fresh mammal blood is separated into red blood cells (RBCs) and plasma by centrifugation.

RBCs are washed with KRL buffer then placed in contact, 3 hours before evaluation, with non-treated plasma (control) and treated plasma samples. The treatment is to bubble peroxidizing and non-peroxidizing volatile part of an organic essential oil of turpentine into the plasma samples, during 3 minutes.

Expended essential oil of turpentine came from a closed, half full bottle several years old. Values of the figure are mean values $\pm S D$; $\mathrm{n}=4$ for the control plasma, $\mathrm{n}=4$ for non-peroxidizing plasma and $\mathrm{n}=6$ for peroxidizing plasma.

$\mathrm{p}<0.05$ peroxidized and non-peroxidizing plasma versus the control one.

Fig. 3. Average levels of glycated hemoglobin from ex-vivo mammal blood — second study.

expended essential oil - in other words, the essential oil of turpentine devoid of the most volatile components (a lab analysis [2] specified these volatile components as $\alpha$ - and $\beta$-pinenes).

Three conclusions were drawn from these observations:

1. Since fresh or oxidized terpenes-rich oil acted positively on glycated hemoglobin levels and the expended oil did not, the ability of the essential oil of turpentine to improve cell oxygenation is due to the volatile components,

2. Since peroxidized or oxidized terpenes-rich oil had a positive effect on glycated hemoglobin levels, and the non-peroxidized one did not; it appears that oxygen is the agent that acts to oppose glycation of hemoglobin in mammals and in the ex-vivo experiments. 
3. For the same reasons, it appears that oxygen is also able to facilitate a reduction of the glycated hemoglobin levels in the ex-vivo experiments.

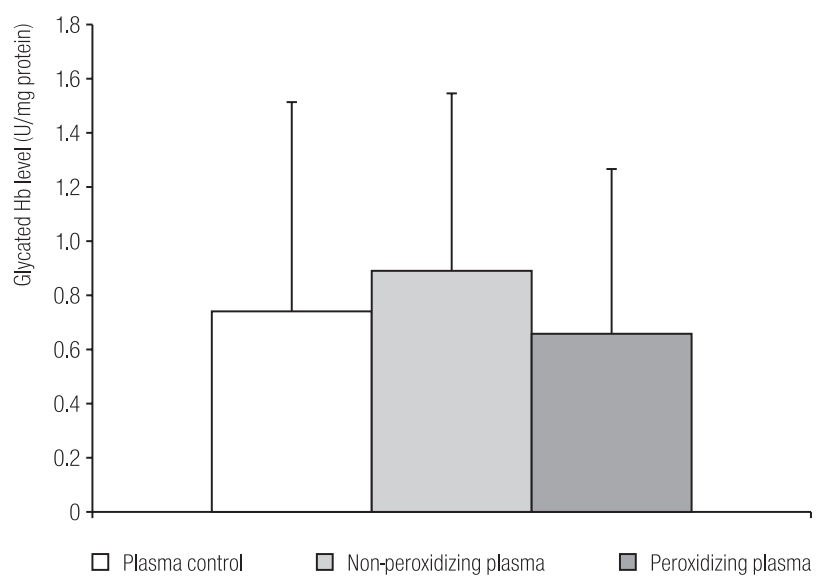

Fresh mammal blood is separated into red blood cells (RBCs) and plasma by centrifugation.

RBCs are washed with KRL buffer then placed in contact, 3 hours before evaluation, with non-treated plasma (control) and treated plasma samples. The treatment is to bubble peroxidizing and nonperoxidizing volatile part of an organic essential oil of turpentine into the plasma samples, during 3 minutes. The expended essential oil of turpentine came from old, post-dated essential oil.

Values of the figure are mean values $\pm \mathrm{SD} ; \mathrm{n}=3$ for each group; there are no statistical differences among the samples.

Fig. 4. Average levels of glycated hemoglobin from ex-vivo mammal blood — third study.

\section{DISCUSSION}

The original potential of the essential oil of turpentine:

\section{An anti-aging wild card}

After nickel, perfumes are the most widespread allergenic substances in the world [7]. This characteristics is connected with the fact that the majority of oils are sensitive to oxidation [8]. However, in some oils, like the essential oil of Chaulmoogra [9] — and in turpentine - aging/oxidation (for the authors, aging implies oxidation) makes the therapeutic coefficient of these compounds very favorable [10]. The ability of essential oil of turpentine to capture and deliver oxygen has been known since the work of Berthelot [11]. This essential oil is thus able to enhance the rate of saturation of $\mathrm{HbO} 2$ [12] and of $\mathrm{PaO} 2$ [13]. This capability was confirmed by the work of Mercier et al. utilizing the Bol d'Air Jacquier® device (oxidized vapor of turpentine used to fight against cellular hypoxia). The unique distinction of the Bol d'Air® breathing method is that it can maintain a moderate increase of the oxygen rate at the cellular level, not only during the inhalation period, but also subsequently [2,3].

Since the fresh essential oil demonstrated this capability - and the expended oil did not, we can surmise that the cell oxygenation capability can be attributed to the most volatile components of the oil (i.e. it is due to the capability of the alpha and beta pinenes to be peroxidized).

With or without turpentine, a better oxygen rate acts positively on glycated proteins, either for rats or blood sample. There is a known relationship between diabetes and hypoxia [14]. However, our experiments enlighten for the first time (as far as we know) a direct relation between oxygen and a lower glycated hemoglobin level (in organisms as well as in ex-vivo experiments). Breathing the alpha-pinenes (i.e. the major part of volatile turpentine) may also aid in the treatment of diabetes (the plant Nigella sativa, whose extract is able to partially revive the Langerhans $\beta$ cells, also contains a great portion of this product [15]). And finally, breathing the peroxidized vapor non only leads to better cell oxygenation, but also helps to prevent free radical damage (studies done with healthy mammals) $[2,3]$.

\section{The importance of a reduced glycated protein level}

Glycation is the pathologic binding of glucose to proteins in the body. It causes protein cross-linking and consequent loss of function [16]. These non-functional proteins, known as Advanced Glycation End Products (AGEs) are the origin of numerous undesirable effects. In the first place, glycated proteins enhance chemical reactivity [17], making them major contributors to oxidative stress. For example, AGE-damaged proteins intravenously infused into healthy laboratory rats dramatically enhanced the levels of pro-inflammatory 
cytokines, causing inflammatory damage usually only seen in aged or diabetic animals [18]. Secondly, they damage tissues throughout the body by degrading the structure and function of the cell membranes [19]. Cross-linked proteins cannot function normally and therefore impair essential membrane functions such as fluidity, electrochemical conduction signaling and regulation of the fluid and electrolyte flow [20]. If structural proteins such as collagen are affected, glycation end products contribute to the loss of flexibility and youthful elasticity, strength of blood-vessel walls as well as skin elasticity, leading to the unsightly sagging and wrinkling of the skin. Lengthened wound healing time and increased susceptibility to infection associated with aging and the progressive age-induced decline in kidney function are also examples of the results of protein glycation. Glycation on the optic lens results in cataracts [21]. When AGE-induced cross-linking occurs in proteins that form the cells' internal structures, cells lose the ability to transport chemical signals internally, impairing numerous cell functions. The loss of these cell functions, sometimes leading to cell death, especially in brain tissues, contributes to neurodegenerative diseases such as Alzheimer's disease [22]. The rate at which proteins are subjected to glycation reactions is a significant factor in mortality.

Diabetes, in particular, inflicts damage to tissues throughout the body by accelerating toxic glycation reactions. In patients with type 2 diabetes, aging occurs at an accelerated rate. Glycation is one of the most important factors responsible for this acceleration of the aging process. There is a striking similarity between the complications of diabetes and the negative changes that are commonly associated with aging [23-25].

\section{CONCLUSION}

For all these reasons, developing a method making it possible to break glycated protein cross-linkage, leads to reversing this aspect of the aging mechanism and is also a step in the direction of effective treatment for diabetes.
Several proven methods exist to slow down toxic glycation processes. For example, research supports the ability of pyridoxamine (vitamin B6) to prevent chronic disease and inhibit disease progression. This vitamin is effective when there is damage resulting from glycation: age-related problems like skin wrinkling, atherosclerosis, chronic inflammation, kidney failure, diabetic complications and Alzheimer's disease [26]. However, nothing can completely arrest glycation nor reduce the glycated protein levels. We feel that testing oxygen capability can be beneficial (besides other methods of diabetes prevention or with other curative plans), even if it looks like a "return to the basics".

\section{ACKNOWLEDGEMENTS}

Several people have been instrumental in enabling this project to be completed. We would like to thank Madame Marie-Laure Delanef, the General Manager of Holiste Laboratory, and especially Bernard Colnat and Dr Dan C Kenner for rereading the article.

\section{REFERENCES}

1. Jacquier R. From atom to life. Paris: Guy Trédaniel Ed.; 2008 [in French].

2. Mercier B. Bol d'Air Jacquier@: biological and antiradicalizing effects of peroxidizing terpenes $[\mathrm{PhD}$ thesis]. Dijon: University of Burgundy; 2008. p. 440-16 [in French].

3. Mercier B, Prost J, Prost M. Antioxidant Activity of Bol d'Air Jacquier® Breathing Sessions in Wistar Rats - First Studies. Int J Occup Med Environ Health 2008;21(1):31-46. DOI 10.2478/v10001-008-0003-2.

4. American Institute of Nutrition. Guidelines for describing diets for experimental animals. J Nutr 1987;117:16-7.

5. CEC Council of European Communities. Council instructions about the protection of living animals used in scientific investigations. Off J Eur Common (JO86/609/CEE) 1986;358:1-28.

6. Habeeb AF. Determination of free amino groups in proteins by trinitrobenzenesulfonic acid. Analyt Biochem 1966;14:328-36. 
7. Groot AC de, Frosch PJ. Adverse reactions to fragrances. A clinical review. Contact Dermatitis 1997;36:57-86.

8. Karlberg AT, Bergström MA, Börje A, Luthman K, Nilsson JL. Allergic contact dermatitis-formation, structural requirements, and reactivity of skin sensitizers. Chem Res Toxicol 2008;21(1):53-69.

9. Lefèvre R, Baranger P. Peroxides and polyphenol derivatives in the treatment of cancer. G Ital Chemioter 1956;3(3-4): 397-407 [in French].

10. Kleinschmidt J, Römmelt H, Zuber A. The pharmacokinetics of the bronchosecretolytic ozothin after intravenous injection. Int J Clin Pharmacol Ther Toxicol 1985;23(4):200-3.

11. Berthelot M. Vegetable and agricultural chemistry. Vol. 3. Paris: Masson Paris Ed.; 1899. p. $476-96$ [in French].

12. Chalchat JC, Garry RP, Michet A, Bastide P, Malhuret R. Correlation between chemical composition and pesticide activity. I. Effect of several chemotypes of essential oil of Pinus sylvestris on Escherichia coli. Plantes Méd Phytothér 1987;XXI(1):26-35.

13. Schafer R, Schafer W. Percutaneous absorption of various terpenes - menthol, camphene, limonene, isoborneol-acetate, alpha-pinene - from foam baths. Arzneimittelforschung 1982;32(1):56-8 [in German].

14. Yeh HC, Punjabi NM, Wang NY, Pankow JS, Duncan BB, Cox CE, et al. Cross-sectional and prospective study of lung function in adults with type 2 diabetes: the Atherosclerosis Risk in Communities (ARIC) study. Diabetes Care 2008;31(4):741-6.

15. Kanter M, Meral I, Yener Z, Ozbek H, Demir H. Partial regeneration/proliferation of the beta-cells in the islets of Langerhans by Nigella sativa L. in streptozotocin-induced diabetic rats. Tohoku J Exp Med 2003;201(4):213-9.

16. Onorato JM, Jenkins AJ, Thorpe SR, Baynes JW. Pyridoxamine, an inhibitor of advanced glycation reactions, also inhibits advanced lipoxidation reactions. J Biol Chem 2000;275:21177-84.

17. Suji G, Sivakami S. DNA damage during glycation of lysine by methylglyoxal: assessment of vitamins in preventing damage. Amino Acids 2007;33(4):615-21.

18. Prasad R, Lakshmi AV, Bamji MS; Impaired collagen maturity in vitamins $B 2$ and $B 6$ deficiency-probable molecular basis of skin lesions. Biochem Med 1983;30(3):333-41.

19. Nakagawa K, Ibusuki D, Yamashita S, Miyazawa T. Glycation of plasma lipoprotein lipid membrane and screening for lipid glycation inhibitor. Ann NY Acad Sci 2008;1126: 288-90.

20. Williams ME, Bolton WK, Khalifah RG, Degenhardt TP, Schotzinger RJ, McGill JB. Effects of pyridoxamine in combined phase 2 studies of patients with type 1 and type 2 diabetes and overt nephropathy. Am J Nephrol 2007;27(6):605-14.

21. Padival S, Nagaraj RH. Pyridoxamine inhibits maillard reactions in diabetic rat lenses. Ophthalmic Res 2006;38(5): 294-302.

22. Kojro E, Postina R. Regulated proteolysis of RAGE and AbetaPP as possible link between type 2 diabetes mellitus and Alzheimer's disease. J Alzheimers Dis 2009;16(4):865-78.

23. Kopf D, Frölich L. Risk of incident Alzheimer's disease in diabetic patients: a systematic review of prospective trials. J Alzheimers Dis 2009;16(4):677-85.

24. Gul A, Rahman MA, Salim A, Simjee SU. Advancedglycation end products in senile diabetic and nondiabetic patients with cataract. J Diabetes Complications 2009;23(5):343-8.

25. Makita Z, Yanagisawa K, Kuwajima S, Yoshioka N, Atsumi T, Hasunuma Y, et al. Advanced glycation endproducts and diabetic nephropathy. J Diabetes Complications 1995;9(4): 265-8.

26. Faloon W. FDA Seeks to Ban Pyridoxamine. Life Extension 2009; July:7-12.

This work is available in Open Access model and licensed under a Creative Commons Attribution-NonCommercial 3.0 Poland License - http://creativecommons.org/ licenses/by-nc/3.0/pl/deed.en. 